УДК 378.147

\title{
Т.А. Борзова
}

Владивостокский государственный университет экономики и сервиса Владивосток. Россия

\section{Уроки пандемии: цифровая трансформация высшего образования в формате удаленного обучения}

\begin{abstract}
Актуальность выбранной темы исследования обусловлена радикальными изменениями в самой организации учебного процесса во всех вузах страны в связи с пандемией COVID-19. За прошедший 2019-2020 учебный год и первый семестр 2020-2021 практически все ведущие вузы страны массово были вынуждены перейти на дистанционный формат обучения с применением той или иной электронной образовательной среды. Такой резкий переход на дистанционное обучение вскрыл много болевых точек всей системы образования России - система показала недостаточную подготовку участников учебного процесса к работе в условиях изоляции. Педагогические коллективы, студенчество, администрация высших учебных заведений России столкнулись с целым рядом проблем, при анализе которых можно выделить главные причины их появления и разработать методические рекомендации по апробации и внедрению новых форм онлайнвзаимодействия преподавателя и студента. В статье анализируется восприятие образовательных дисциплин основными участниками учебного процесса ВГУЭС в условиях экстренного перехода на удаленный формат обучения. Удаленное обучение становится одним из главных факторов реформирования образовательного процесса в вузах. В этой связи интересен анализ успешного опыта адаптации к удаленному обучению с применением электронно-образовательной среды Moodle. Проанализированы сильные и слабые стороны этого процесса, сделан вывод о том, что в системе современного высшего образования дистанционный формат обучения может считаться формой, которая дополняет и усиливает учебно-образовательный потенциал получаемого образования. Устойчивая тенденция, стремительное развитие онлайн-коммуникаций должны стимулировать вузы к внедрению в учебный процесс инновационных форм взаимодействия, привлекая преподавателей и студентов к их творческому освоению.
\end{abstract}

Ключевые слова и словосочетания: COVID-19, интерактивные технологии, онлайн-обучение, дистанционное обучение, смешанное обучение, цифровизация

Борзова Татьяна Александровна - канд. культурологии, доцент кафедры русского языка; e-mail: Tatyana.Borzova@vvsu.ru 
учебного процесса, электронная образовательная среда (эос), Moodle, технология «перевернутый класс» (flipped classroom), мотивация, риски удалённого обучения.

\title{
T.A. Borzova
}

Vladivostok State University of Economics and Service

Vladivostok. Russia

\section{Lessons from the pandemic: digital transformation of higher education through in remote learning}

\begin{abstract}
The relevance of the chosen research topic is due to radical changes in the very organization of the educational process in all universities in the country in connection with the COVID-19 pandemic. Over the past 2019-2020 and the first semester of the 2020-2021 academic years, almost all of the country's leading universities were massively forced to switch to distance learning using one or another electronic educational environment. Such a sharp transition to distance learning revealed quite a lot of pain points of the entire education system in Russia - the system showed insufficient preparation of participants in the educational process to work in isolation. Pedagogical teams, students, administrations of higher educational institutions of Russia have faced a number of problems, in the analysis of which it is possible to single out the main reasons for their appearance and develop methodological recommendations for approbation and implementation of new forms of online interaction between teacher and student. The purpose of the study is to analyze the perceptions of the main participants in the educational process of VSUES in the context of an emergency transition to a remote learning format. Distance learning is becoming one of the main factors in the reform of the educational process in universities. In this regard, it is interesting to analyze the successful experience of adaptation to distance learning using the electronic educational environment Moodle. The strengths and weaknesses of this process are analyzed, it is concluded that in the system of modern higher education the distance learning format can be considered a form that complements and strengthens the educational potential of the education received. A steady trend, the rapid development of online communications, should stimulate universities to introduce innovative forms of interaction into the educational process, attracting teachers and students to their creative development.
\end{abstract}

Keywords: COVID-19, interactive technologies, online learning, distance learning, blended learning, digitalization of the educational process, electronic educational environment, Moodle, flipped classroom technology, motivation, risks of distance learning.

\section{Введение}

Цифровая трансформация - довольно злободневный тренд современного общества во всех сферах окружающей действительности, в том числе и в образовании. Но говорить о каких-либо долгосрочных прогнозах и перспективах, наработанных и успешно внедренных методах и программах на современном этапе не приходится. 
«Общество постепенно осознает масштаб возникающих проблем. Последние десятилетия политики и ученые неоднократно обращали внимание на важность улучшения качества образования. Во всех развитых странах мира прошли образовательные реформы, при этом выделялись средства и прикладывались заметные усилия с целью повысить результативность образовательных систем. И все же <...> системам образования развитых стран не удается справиться с задачей подготовки людей к жизни в условиях цифровой революции» [18].

С весны 2020 года система образования России экстренно и стремительно вошла в дистантный формат, который преимущественно реализовался посредством активизации различных электронно-образовательных систем и интерактивных инструментов. Этот переход не только позволил проверить результаты уже проведенной большинством вузов страны цифровизации учебного процесса, но и стал своеобразным регулятором интенсификации цифровой трансформации образования, которая является одним из основных требований современного образовательного стандарта (ФГОС $3++)$.

Отметим, что влияние современного состояния дел в образовательной системе страны на качество самого образования еще только предстоит оценить. Однако уже сейчас представляется возможным изучить впечатления непосредственных участников учебного процесса - преподавателей и студентов - от вынужденного и «навязанного» ситуацией процесса обучения в рамках дистанционного формата образования в условиях изоляции.

Полагаем, что экстренный переход образовательных учреждений страны на удаленный формат является весьма адекватной реакцией всей системы образования России на агрессивный вызов времени.

В отличие от всех предыдущих реформ и модернизаций эта обстановка характеризуется целым рядом особенностей.

Во-первых, по степени охвата процесс распространился на все уровни функционирования образовательной системы России.

Во-вторых, не было практически никакого подготовительного и тестового этапа к такому массовому переходу на дистанционный формат.

B-третьих, весь процесс перехода на новый формат обучения был проведен в сжатые сроки и одновременно на всей территории образовательного пространства России.

Здесь следует обратить внимание на то, что в мировой практике образования данная форма дистанционного обучения с применением обширного ресурса инфокоммуникационных средств имеет достаточно продолжительную историю. Накопленный мировой опыт дистанционного образования позволяет нам говорить о развитии этого процесса в следующих направлениях: 1) дистанционное обучение в рамках всемирной системы Интернет; 2) активное введение в образовательный процесс мобильных и облачных технологий, открытых образовательных платформ, способствующих целенаправленному выбору самими учащимися индивидуальной траектории обучения с учетом потребностей и особенностей каждого и, соответственно, организации своего автономного обучения [12]. 
Важно отметить, что такие интерактивные технологии обеспечивают учащихся возможностью работать и учиться вне вузовской аудитории в любое удобное для обучения время [6], что позволяет быстро диагностировать и оценивать весь спектр проблемных вопросов в процессе обучения, используя в качестве инструмента мгновенной обратной связи мобильную интерактивную среду. Это также дает возможность в ходе учебного процесса вносить корректировки в формы его ведения, стимулирует появление новых форм демонстрации и предъявления учебного материала (видеоконференции, вебинары, созданные самими студентами, моблоги и др.), а также помогает внедрять новые форматы интерактивных занятий с помощью интернет-приложений дополнительной реальности и геолокации [6].

В системе высшего образования России уже достаточно продолжительное время ведутся разработки и активно внедряются электронно-образовательные ресурсы (ЭОС), электронно-учебные курсы (ЭУК), электронно-учебные методические курсы (ЭУМКД) по дисциплинам учебных планов каждого вуза различных направлений и уровня подготовки обучающихся.

Успешный практический опыт внедрения в учебный процесс цифрового формата позволил системе высшей школы России в целом достаточно гармонично и безболезненно перейти в формат удаленного обучения с применением целого спектра электронных ресурсов. Однако вместе с этим новая реальность позволила довольно быстро обнаружить ряд проблем, связанных с различными нюансами функционирования образовательной деятельности того или иного учебного заведения.

В одном из своих интервью информационному агентству РБК в апреле 2020 года министр науки и высшего образования Российской Федерации В.Н. Фальков обратил внимание на сложности в работе преподавателей в удаленном формате обучения, касающиеся организации коллективной работы, поддержания внимания студентов, при этом подчеркнул, что сам процесс обучения должен продолжать традиции обычного, т.е. задача преподавателей и в новых условиях «сделать интересным обучение в формате, когда у тебя, по существу, эмоциональные и интеллектуальные моменты идут асинхронно» [9].

Из этого следует, что имеющийся опыт создания, внедрения и применения электронных курсов, интерактивных учебных материалов с использованием ЭОС и т.п. оказался на практике в удаленном формате недостаточным для организации полноценного формата обучения. В результате перехода к полной «удаленке» выявились существенные противоречия между различными подходами к проектированию и реализации всеми участниками образовательного процесса и недостаточной подготовленностью преподавателей и студентов к работе в данном формате обучения.

Таким образом, ключевая проблема исследования касается выявления основных объективных и субъективных причин, препятствующих участникам образовательного процесса в использовании контактного взаимодействия в условиях дистанционного формата обучения. 
Цель исследования - на основании опыта обучения в дистанционном формате и впечатлений основных участников учебного процесса (на примере Владивостокского государственного университета экономики и сервиса) обозначить ключевые проблемы, с которыми столкнулись преподаватели и студенты ВГУЭС в условиях полного перехода на дистанционный формат обучения, и предложить новые модели образовательных форм при полной цифровизации учебного процесса.

\section{Обсуждение проблемы}

Массовый переход отечественной системы образования высшей школы к удаленному формату контактного обучения с использованием электронных интерактивных технологий позволил увидеть не только большие возможности такой организации учебного процесса, но и связанные с ним ограничения.

О достоинствах и слабых сторонах «полного» дистанционного образования писали еще задолго до наступления пандемийных процессов, когда оно рассматривалось на примере отдельных учебных заведений, где обучение велось только с использованием онлайн-взаимодействия (открытые учебные заведения, виртуальные университеты и т.п.).

Однако в настоящий момент удаленное обучение из альтернативного превращается в обязательный формат [2] профессионального образования в условиях, когда процесс цифровизации учебного процесса полностью не внедрен и не освоен практикой высшей школы [16]. От научных дискуссий о преимуществах и недостатках применения цифрового образования вузы вынуждены были в экстренном порядке переходить к масштабному внедрению новых методов обучения, независимо от готовности преподавателей и студентов к использованию интернет-технологий в практике обучения $[1 ; 8 ; 10]$. Практические результаты исследований демонстрируют следующее: наблюдается тенденция снижения фактора мотивации обучения, происходит потеря самоценности знаний, содержание образования и обучения в целом упрощается. Такое положение дел чревато потерей альтернативных подходов к содержанию самого образования. Как подчеркивает А.И. Ракитов, «формализация профессиональных знаний и снижение их разнообразия могут в определённых условиях негативно сказаться в дальнейшем на практической деятельности выпускников вузов» [15].

В свою очередь И.А. Колесникова акцентирует внимание на том, что процесс тотальной цифровизации всего образования иллюстрирует, как, с одной стороны, происходит разделение, обособление курсов, а с другой - наблюдается довольно дилетантский подход к созданию самих электронных курсов новых дисциплин, при этом качество этих курсов и структурно-смысловая логика предмета не соответствуют требованиям высшего образования. Помимо «базовых учебных источников в процесс обучения привлекается большое количество игр, информации из социальных сетей, открытых сайтов и приложений, что может привести к поверхностному изучению студентами их предмета, его упрощению и примитивному видению. В итоге происходит сдвиг способов познания мира - от теоретического осмысления к непосредственному спонтанному действию, не всегда осознанному. В потоке стихийного взаимодействия с информацией научные факты и объективное знание постепенно теряют своё значение» [11]. 
По данным современных исследований, «вынужденный» формат всеобщего онлайн-обучения ожидает от современного студента способности самообучаться, развивать собственную мотивацию к обучению и владеть необходимыми для этого навыками. Однако следует отметить, что далеко не каждый учащийся способен осваивать предмет самостоятельно, особенно при овладении сложными курсами. Только 10-25\% учащихся в формате удаленного обучения с использованием дистанционных технологий завершают обучение удовлетворительно [11].

Многие исследователи констатируют факт, что в условиях полного удаленного формата обучения практически невозможна реализация одного из главных постулатов педагогической мысли - воспитывающей, формирующей, развивающей и продвигающей роли самого процесса обучения.

Процесс воспитания в обучении играет очень важную роль, т.к. подразумевает направленное развитие личности обучающегося, формирование эмоционально-ценностных установок при морально-нравственном выборе самого учащегося в различных ситуациях; проживание и проявление эмпатии в неординарных ситуациях и новых созданных условиях обучения на основе восприятия социальных понятий и установок. В процессе обучения в формате дистанционного общения утрачивается воспитание нравственности учащегося, т.к., к сожалению, в данном формате оно заключается лишь в принятии уведомления о том, что считается в социуме плохим или хорошим. Как заметил А.А. Вербицкий, «можно хорошо знать нормы морали и быть безнравственным, плохо воспитанным, взяточником, преступником» [5; 14].

Недостаток, а иногда и полное отсутствие живого диалога между основными участниками образовательного процесса в условиях удаленного формата образования, цифровое подражание традиционному «живому» общению, которое неотделимо от человека, ведут к возникновению проблемы передачи косвенного, скрытого, негласного знания [15].

Бесспорно, возможности современных интернет-технологий обладают высокой оперативностью и избавляют современных студентов от напряженной умственной работы в поисках необходимой информации. Это приводит к тому, что у учащихся вырабатывается привычка к поиску быстрых ответов в сети Интернет и, как следствие, утрачивается навык работы с объемной информацией текстов. Многие специалисты, занимающиеся вопросом речевой активности, замечают факты деградации речи учащихся, а вместе с ней и мышления.

Зарубежные исследователи обращают свое внимание на то, что в целом мобильные технологии освободили нас от многих ежедневных проблем, однако в итоге запустили механизм разрушения: освободив от умственного напряжения, искусственный разум ослабляет и губит нас, поскольку мы теряем способность думать, размышлять, анализировать и делать выводы [13].

Таковы, на наш взгляд, основные проблемы дистанционного обучения, на которые обращают внимание отечественные и зарубежные исследователи.

\section{Эмпирическое исследование}

Перейдем к рассмотрению некоторых предварительных заключений, основанных на опыте работы Владивостокского государственного университета эко- 
номики и сервиса в условиях удаленного обучения в связи с вызовом нашего времени - ограничений, связанных с вирусом COVID-19. Нас волновал вопрос отношения самих участников учебного процесса - студентов и преподавателей к данному формату получения и трансляции знаний.

К началу перехода на удаленный формат на кафедре русского языка ВГУЭС практически все дисциплины характеризовались смешанной технологией обучения в LMS MOODLE [13]. В условиях самоизоляции учебный процесс стал осуществляться на основе электронных курсов дисциплин и электронных учебнометодических комплексов.

Для выявления различных точек зрения на новую форму организации учебного процесса в начале учебного 2020-2021 года автором статьи был проведен опрос 240 студентов, имеющих опыт удаленного обучения и осваивающих основные программы по очной форме обучения гуманитарных направлений бакалавриата «Сервис», «Лингвистика», «Экономика», «Юриспруденция», «Туризм», «Экология», «Дизайн», «Информационные технологии», и 68 преподавателей ВГУЭС.

Идентификаторы, по которым респондентам предлагалось признать и оценить собственную готовность к переходу на дистанционный формат обучения, были взяты из материалов опубликованных исследований ведущих отечественных ученых $[1 ; 8 ; 10]$. Опросный лист включал в себя набор закрытых вопросов с множественным выбором вариантов ответов.

В дистанционном формате обучения при удаленной форме проведения занятий основными проблемами, снижающими результативность занятий, оказались техническая возможность реализации практических занятий в ЭОС, условия обучения по месту изоляции и уровень владения онлайн-сервисами всеми участниками образовательного процесса.

Как показали ответы респондентов, более $80 \%$ студенческого сообщества оказались готовы к постоянному использованию интерактивных инструментов в учебном процессе. Однако преподавательский состав продемонстрировал готовность в этом вопросе на $35 \%$. Именно преподаватели не смогли сразу перейти на массовое применение дистанционного обучения с удаленным доступом с применением электронно-образовательных технологий.

95\% студенческой аудитории имели неограниченный доступ к личному мобильному устройству, но лишь у $45 \%$ респондентов данные устройства полностью обеспечивали выполнение всех задач обучения (отсутствие веб-камеры, неработающие микрофоны, наушники, небольшой экран и т.д.).

Достаточно часто речевое взаимодействие между преподавателем и студентами зависело не только от технического состояния личного интерактивного инструментария, но и от самого качества интернет-связи, которое студентами и преподавателями было оценено как среднее (55\%).

Вопросы, связанные с дополнительными расходами на организаџию обучения, оказались незначительными для респондентов (8\%), т.к. компенсировались за счет экономии средств на транспорт, обеды и т.п. 
Один из вопросов, на который были получены противоположные ответы респондентов, касался социально-бытовых условий. $90 \%$ студентов продолжили образовательный процесс в достаточно комфортных условиях, лишь $10 \%$ отметили, что некоторые факторы им мешали заниматься (телефоны, наличие дома домочадцев и домашних животных, музыка, хорошая погода, запах еды и т.п.). Результаты ответов преподавателей $(84 \%)$ показали, что дома сложно было добиться комфортных условий для проведения занятий, поскольку необходимо было совмещать социальные роли и выполнять обязанности отца/матери и т.п. Сложно было определить зону личного и рабочего пространства. Кроме того, у преподавателей практически отсутствовала возможность регламентировать рабочее и свободное время (92\%).

В связи с цифровизацией образовательного процесса возник вопрос о владении циифровой компетенцией всеми участниками процесса обучения. Отвечая на вопрос о владении данной компетенцией, 94\% студентов посчитали себя уверенными пользователями интернет-ресурсов, которые владеют различными средствами построения общения в цифровой среде. Более $80 \%$ разбираются и используют в своей работе мультимедийные технологии и различные функции электронных ресурсов.

Однако реальность нашего времени показывает, что продвинутое владение цифровой компетенцией у молодого поколения отнюдь не связано со стремлением к образованию или самообразованию. К сожалению, новое поколение студентов использует интерактивные средства связи в большинстве случаев для игр, просмотра роликов и фильмов, «залипания» в социальных сетях и чата в различных мессенджерах. Также Интернет ими используется для того, чтобы «что-то скачать» или «что-нибудь купить». Большинство студентов находятся постоянно в активном онлайн-режиме и предпочитают проводить в виртуальном формате большую часть своего времени (иногда до 12-14 часов в день). Подобное поведение молодого поколения отмечают многие исследователи и приходят к заключению, что такая зависимость от гаджетов может негативно сказаться на социально-гражданском, познавательном и эмоциональном развитии студентов. Сравнительно реже заходят в Интернет «что-нибудь почитать». Многие студенты, пребывая в активном онлайн-режиме более шести часов в день, предпочитают виртуальный формат общения и досуг в виде игр. Интернет-зависимое поведение негативно сказывается на их социальном, когнитивном и эмоциональном развитии [14].

Заметим, что сама организация учебного процесса в удаленном режиме стала более трудоемкой. Возросли психологические и физические затраты преподавательского состава при организации и проведении практических занятий в онлайн-режиме. Преподаватели были вынуждены постоянно находиться в онлайнрежиме: проводить практические занятия в часы расписания, проверять выполнение самостоятельных работ студентов, постоянно находиться на мобильной связи, проводить консультации, готовить и предъявлять презентации, вносить корректировки в ЭУМКД, проводить вебинары, участвовать в совещаниях и т.д. Из этого можно заключить, что преподаватели как центральное звено учебного 
процесса должны были одновременно совмещать и выполнять роли воспитателя, методиста, организатора, наставника, модератора интерактивно-электронного образовательного пространства [1].

Как показали результаты проведенного анкетирования, в формате дистанционного обучения в условиях самоизоляции вклад в образовательный процесс преподавателей оказался гораздо объемнее тех стараний, которые показывают студенты при изучении нового материала, выполнении и сдаче в срок обязательных заданий.

Тем не менее, 19\% учащихся постоянно испытывали нехватку времени на подготовку к практическим занятиям, а $28 \%$ не смогли вовремя изучить теоретический материал.

Для студента измеритель, величина результативности курса - образовательное достижение, показатель, т.е. баллы. Для преподавателя показатель эффективности курса - это наличие постоянной, контактной, положительной обратной связи. Ответы большинства преподавателей в анкете показали, что педагоги не чувствуют удовлетворения от занятий в онлайн-режиме, хотя результаты обучения, согласно рейтинговой успеваемости университета, в целом неплохие - $94 \%$. Причины, которые они указали в качестве пояснения: недостаток прямой обратной связи (77\%); отсутствие возможности отслеживать эмоциональную реакцию обучающихся (89\%); недостаток диалога со всей аудиторией $(92 \%)$.

Преподаватели (88\%) отмечали еще тот факт, что в режиме дистанционного формата общения с аудиторией у них отсутствовала возможность проверить, что сейчас делает студент, чем занимается, какие средства электронного обучения использует. Сложно было установить степень самостоятельности при выполнении тестовых и контрольных заданий, что, собственно, не отвечало объективности оценивания результатов обучения.

В новых условиях ограниченного пространства при определенном временном лимите отсутствие внешнего контроля за качеством выполнения заданий ослабляет мотивацию студенческого сообщества к самостоятельному выполнению определенных задач.

В формате дистанционного проведения занятий практически не удалось адаптировать устную форму общения между участниками онлайн-встреч. По техническим причинам необходимо было совмещать синхронное и последовательное взаимодействие, т.к. приходилось регулировать количество участников, что особенно проявилось при проведении групповых проектов устного формата (совещания, переговоры, групповые презентации, дискуссии, собеседования и т.п.). Полноценный диалог в данных условиях практически невозможен. И студенты $(88 \%)$ и преподаватели $(91 \%)$ отметили данный факт как недостаток. По этой причине многие преподаватели устный контент заданий заменяли письменными работами, и этот однотипный, монотонный вид работы снижал мотивацию студентов. Согласно результатам анкетирования $57 \%$ студентов признали эффективность заданий в устной форме презентации учебного материала минимальной, 35\% оценили ее как «среднюю», однако для $91 \%$ респондентов эффективность письменных форм была «высокой». 
Несмотря на то, что доступ к электронным ресурсам для студентов (более 90\%) был свободным, это не послужило поводом для стимулирования их познавательной деятельности.

Положительные результаты образовательного процесса определяются его эффективностью. Стоит обратить внимание, что эффективность зависит не столько от качества и количества электронных учебных материалов, сколько от потребности обучающихся в них [3].

Итоговый вопрос анкеты для всех респондентов звучал так: «На сколько в целом вы удовлетворены организацией процесса обучения в удаленном формате с использованием электронных технологий?». Ответ на данный вопрос показал, что больше половины всех опрошенных студентов данный формат обучения полностью удовлетворил - 86\%, однако $35 \%$ респондентов отметили не очень удобные платформы и работу ЭОС (Moodle). Лишь 16\% опрошенных ответили, что не удовлетворены удаленным форматом проведения занятий. В качестве пояснения последние добавили, что это было продиктовано тем, что «практические занятия не проводятся в привычном режиме, потому что преподаватель просто дает задание в учебнике или в ЭОС, а сам отключается»; «сами преподаватели не всегда были готовы к такому формату»; «расписание часто не соблюдалось» и др. В целом большинство опрошенных студентов были удовлетворены организацией учебного процесса в дистанционном формате.

Преподаватели в своих ответах на данный вопрос разделились поровну. Многие быстро освоили новые образовательные технологии и практически безболезненно вошли в новый формат ведения образовательного процесса. Но для половины преподавателей он оказался достаточно проблематичным. Не все смогли принять такой формат обучения, где не было обратной связи со студентами. Отсутствовал контроль выполнения или самостоятельности заданий и т.п.

Учитывая, что переходный период на эту форму обучения был выполнен в короткие сроки, такой итог вполне удовлетворителен. Он показал, что ВГУЭС в оперативном режиме смог адекватно отреагировать на возникший вызов окружающей действительности. Стоит отметить, что университет к началу пандемийных ограничений был уже в целом готов к переходу на дистанционный формат образования, ЭОС достаточно эффективно и успешно использовалась в технологии смешанного обучения всеми структурными подразделениями университета. Кроме того, отделом современных образовательных технологий (ОСОТ) университета были оперативно разработаны инструкции для преподавателей и студентов по освоению бесплатных платформ для проведения занятий в удаленном формате, участия в вебинарах в Google Hangouts Meet и Adobe Connect, a также совещаниях в Google Meet, Voov Meetings (для китайских студентов). Было организовано и проведено оперативное обучение всех преподавателей.

Такой подход к организации учебного процесса позволил учебному управлению качественно осуществлять оперативный контроль по проведению занятий согласно единым критериям и показателям. Выбранные цифровые платформы помогли сделать учебный процесс видимым, достаточно продуктивно реагировать на принятие оперативных и тактических решений. 
Платформы Google Hangouts Meet, Adobe Connect, Voov Meetings обеспечили возможность проведения не только практических и лекционных занятий, но и совещаний, планерок, конференций в режиме видеосвязи. Это позволило корректировать такой фактор, как время, т.е. каждый участник процесса мог попасть на встречу из любого месторасположения.

Однако не обошлось и без проблем организационного характера. В анкетах преподаватели отмечали, что многие занятия начинались и заканчивались не точно по расписанию (в силу объективных и субъективных причин); работа в удаленном формате осложнилась тем, что требовалось более тщательно проектировать каждое занятие от формулирования задач до проведения контроля знаний. Многие преподаватели (89\%) отметили, что время на подготовку одного занятия увеличилось в 2 раза по сравнению с традиционной формой проведения.

Результаты опроса среди студентов и преподавателей ВГУЭС актуализируют проблему качества оптимизации учебного процесса, что в свою очередь требует поиска новых организационно-координирующих механизмов для регуляции взаимодействия преподавателя и учебной группы.

Одно из таких решений мы видим в «сокращении количества одновременно и параллельно изучающих дисциплин» [14]. Этого можно достичь, если перейти на концентрированную модель организации учебного процесса, когда две-три взаимосвязанные дисциплины (например, «Русский язык и культура речи», «Русский язык в деловом общении», «Профессиональная речь и деловая переписка») объединяются в модуль и изучаются параллельно [5].

Все практические занятия в удаленном формате проводились на площадках вебинаров, где преподаватель вынужден был играть роль ведущего. Для того, чтобы у студентов не было потребительского отношения к занятиям (как зрителей), не ослабевала мотивация к обучению, повысилось внимание к каждому блоку занятия, предлагаем вызвать у них интерес к самому процессу обучения и тем самым побудить к совместной научно-познавательной деятельности посредством нового подхода к проведению практических занятий по модели вебинаров. Другими словами, студент должен быть способен и готов не только быть пассивным участником практического занятия в форме онлайн-коммуникации, но и уметь самостоятельно конструировать и проводить вебинары, т.е. создавать объективированный результат обучения - онлайн-продукт профессиональных коммуникаций.

Мы предлагаем ввести в учебный процесс такую форму практического занятия, как проектная деятельность по разработке вебинара на определенную тему для каждого студента или группы. Такая форма занятия поможет преодолеть ограничения раздельного местонахождения, т.к. позволит сочетать в себе различные виды студенческой совместной деятельности [2].

\section{Заключение}

Переход в 2020 году на полный дистанционный формат обучения ускорил, на наш взгляд, виртуализацию образования, что вызвало в системе образования масштабную перестройку всего учебного процесса, в котором в качестве нового фактора выступила модель контактного удаленного обучения с использованием 
ЭОС вуза и интернет-технологий. Такой опыт обязательного и тотального перехода на дистанционный формат обучения не только позволил создать новую модель обучения, которая обладает большими технологическими возможностями, но и помог выявить наиболее проблемные вопросы онлайн-обучения. Наиболее уязвимые места, как показал опрос, затрагивают сферу общения между участниками процесса обучения, а именно: отсутствие «живого», непосредственного контакта между собой. Поэтому удаленный формат обучения побуждает преподавательский состав вузов к поиску новых методических подходов и, прежде всего, к поиску новых моделей эффективного онлайн-общения.

Итак, можно сделать вывод о том, что в системе высшего образования дистанционная форма обучения может рассматриваться и применяться не в качестве основной, а в качестве дополняющей и укрепляющей традиционный базовый формат высшей школы. Несмотря на то, что прогнозы по возвращению к прежнему формату организации обучения еще не ясны, стоит уже сейчас задуматься над вопросом о модели организации образовательного процесса в постпандемийный период.

1. Агранович М.Л. Организация образования в условиях пандемии. Практика стран ОЭСР. - Текст: электронный // Федеральный институт развития образования: [сайт]. URL: $\quad$ https://firo.ranepa.ru/novosti/105-monitoring-obrazovaniya-na-karantine/789agranovich-ekspertiza (дата обращения: 15.12.2020).

2. Базаров Т.Ю. Дистанционное обучение: организация опосредованного общения // Психопедагогика в правоохранительных органах. - 2017. - № 2 (96). - С. 51-56.

3. Борзова Т.А. Преподаватель как основное звено технологии «перевернутый класс» // Высшее образование в России. - 2018. - Т. 27, № 5. - С. 42-49.

4. Вербицкий А. А. Цифровое обучение: проблемы, риски и перспективы. - Текст: электронный // Homo Cyberus. - 2019. - № 1(6). - URL: http://journal.homocyberus.ru/Verbitskiy_AA_1_2019 (дата обращения: 05.01.2021).

5. Трансформация обучения в высшей школе во время пандемии: болевые точки / И.Р. Гафуров, Г.И. Ибрагимов, А.М. Калимуллин, Т.Б. Алишев // Высшее образование в России. -2020 . - Т. 29, № 10. - С. 101-112.

6. Driver P. Pervasive Games and Mobile Technologies for Embodied Language Learning // International Journal of Computer Assisted Language Learning and Teaching. - 2012. Vol. 2, Iss. 4. - P. 23-37.

7. Ибрагимов Г.И., Ибрагимова Е.М., Андрианова Т.М. Теория обучения. - Москва: Владос, 2011. $-383 \mathrm{c}$.

8. Ильченко С. Дистанционный журфак: полюсы и минусы удаленного обучения.Текст: электронный // Журналист: [сайт]. - URL: jrnlst.ru/distance-learning (дата обращения: 03.01.2021).

9. Калюков Е., Доронов И. Фальков анонсировал появление из-за вируса «другого высшего образования». - Текст: электронный // Деловой журнал «РБК»: [сайт]. - URL: https: // www.rbc.ru/society/09/04/2020/ 5e8edde 79a79470 aа3b361f7 (дата обращения: 23.12.2020).

10. Киясов Н., Ларионова В. Дистанционное обучение в экстремальных условиях. Текст: электронный // Интерфакс. Образование: [сайт]. - URL: academia.interfax.ru/analytics/research/4491 (дата обращения: 28.12.2020). 
11. Колесникова И.А. Постпедагогический синдром эпохи цифромодернизма // Высшее образование в России. - 2019. - Т. 28, № 8-9. - С. 67-83.

12. Kukulska-Hulme A. Mobile learning for qualityeducation and social inclusion. IITE Policy Brief. - December, 2010. - 12 p.

13. Новаковская Ю.В. Какое образование нам нужно? // Вестник Московского университета. Педагогическое образование. - 2013. - № 1. - С. 13-30.

14. Цифровое поведение и особенности мотивационной сферы интернет-пользователей: логико-категориальный анализ / И.Н. Погожина, А. И. Подольский, О. А. Идобаева, Т. А. Подольская // Вопросы образования. - 2020. - № 3. - С. 60-94.

15. Ракитов А.И. Высшее образование и искусственный интеллект: эйфория и алармизм // Высшее образование в России. - 2018. - Т. 27, № 6. - С. 41-49.

16. Тихонова Н.В. Технология «перевернутый класс» в вузе: потенциал и проблемы внедрения // Казанский педагогический журнал. - 2018. - № 2. - С. 74-78.

17. Traxler J. Learning in a mobile age // International Journal of Mobile and Blended Learning. - 2009. - № 1(1). - P. 1-12.

18. Уваров А. Ю., Фрумин И.Д. Трудности и перспективы цифровой трансформации образования. - Москва: Высшая школа экономики, 2019. - 342 с.

\section{Транслитерация}

1. Agranovich M.L. Organizaciya obrazovaniya v usloviyah pandemii. Praktika stran OESR. Tekst: elektronnyj // Federal'nyj institut razvitiya obrazovaniya: [sajt]. - URL: https://firo.ranepa.ru/novosti/105-monitoring-obrazovaniya-na-karantine/789-agranovichekspertiza (data obrashcheniya: 15.12.2020).

2. Bazarov T. Yu. Distancionnoe obuchenie: organizaciya oposredovannogo obshcheniya // Psihopedagogika v pravoohranitel'nyh organah. - 2017. - № 2 (96). - S. 51-56.

3. Borzova T. A. Prepodavatel' kak osnovnoe zveno tekhnologii «perevernutyj klass» // Vysshee obrazovanie v Rossii. - 2018. - T. 27, № 5. - S. 42-49.

4. Verbickij A. A. Cifrovoe obuchenie: problemy, riski i perspektivy. - Tekst: elektronnyj // Homo Cyberus. - 2019. - № 1(6). - URL: http://journal.homocyberus.ru/ Verbitskiy_AA_1_2019 (data obrashcheniya: 05.01.2021).

5. Transformaciya obucheniya $\mathrm{v}$ vysshej shkole vo vremya pandemii: bolevye tochki / I. R. Gafurov, G. I. Ibragimov, A. M. Kalimullin, T. B. Alishev // Vysshee obrazovanie v Rossii. - 2020. - T. 29, № 10. - S. 101-112.

6. Ibragimov G. I., Ibragimova E. M., Andrianova T. M. Teoriya obucheniya. - Moskva: Vlados, 2011. $-383 \mathrm{~s}$.

7. Il'chenko S. Distancionnyj zhurfak: polyusy i minusy udalennogo obucheniya. - Tekst: elektronnyj // Zhurnalist: [sajt]. - URL: jrnlst.ru/distance-learning (data obrashcheniya: 03.01.2021).

8. Kalyukov E., Doronov I. Fal'kov anonsiroval poyavlenie iz-za virusa «drugogo vysshego obrazovaniya». - Tekst: elektronnyj // Delovoj zhurnal «RBK»: [sajt]. - URL: https: // www.rbc.ru/society/09/04/2020/ 5e8edde 79a79470 aa3b361f7 (data obrashcheniya: 23.12.2020).

9. Kiyasov N., Larionova V. Distancionnoe obuchenie v ekstremal'nyh usloviyah. -Tekst: elektronnyj // Interfaks. Obrazovanie: [sajt]. - URL: academia.interfax.ru/analytics/research/4491 (data obrashcheniya: 28.12.2020).

10. Kolesnikova I. A. Postpedagogicheskij sindrom epohi cifromodernizma // Vysshee obrazovanie v Rossii. - 2019. - T. 28, № 8-9. - S.67-83.

11. Novakovskaya Yu. V. Kakoe obrazovanie nam nuzhno? // Vestnik Moskovskogo universiteta. Pedagogicheskoe obrazovanie. - 2013. - № 1. - S. 13-30. 
12. Cifrovoe povedenie i osobennosti motivacionnoj sfery internet-pol'zovatelej: logikokategorial'nyj analiz / I. N. Pogozhina, A. I. Podol'skij, O. A. Idobaeva, T. A. Podol'skaya // Voprosy obrazovaniya. - 2020. - № 3. - S. 60-94.

13. Rakitov A. I. Vysshee obrazovanie i iskusstvennyj intellekt: ejforiya i alarmizm // Vysshee obrazovanie v Rossii. - 2018. - T. 27, № 6. - S. 41-49.

14. Tihonova N. V. Tekhnologiya «perevernutyj klass» v vuze: potencial i problemy vnedreniya // Kazanskij pedagogicheskij zhurnal. - 2018. - № 2. - S. 74-78.

15. Uvarov A. Yu., Frumin I. D. Trudnosti i perspektivy cifrovoj transformacii obrazovaniya. Moskva: Vysshaya shkola ekonomiki, 2019. - 342 s.

(ㄱ Т. А. Борзова, 2021

Для цитирования: Борзова Т.А. Уроки пандемии: цифровая трансформация высшего образования в формате удаленного обучения // Территория новых возможностей. Вестник Владивостокского государственного университета экономики и сервиса. - 2021. - Т. 13, № 1. - C. 195-208.

For citation: Borzova T. A. Lessons from the pandemic: digital transformation of higher education through in remote learning, The Territory of New Opportunities. The Herald of Vladivostok State University of Economics and Service, 2021, Vol. 13, № 1, pp. 195-208.

DOI https://doi.org/10.24866/VVSU/2073-3984/2021-1/195-208

Дата поступления: 26.01.2021. 